\title{
Index of places
}

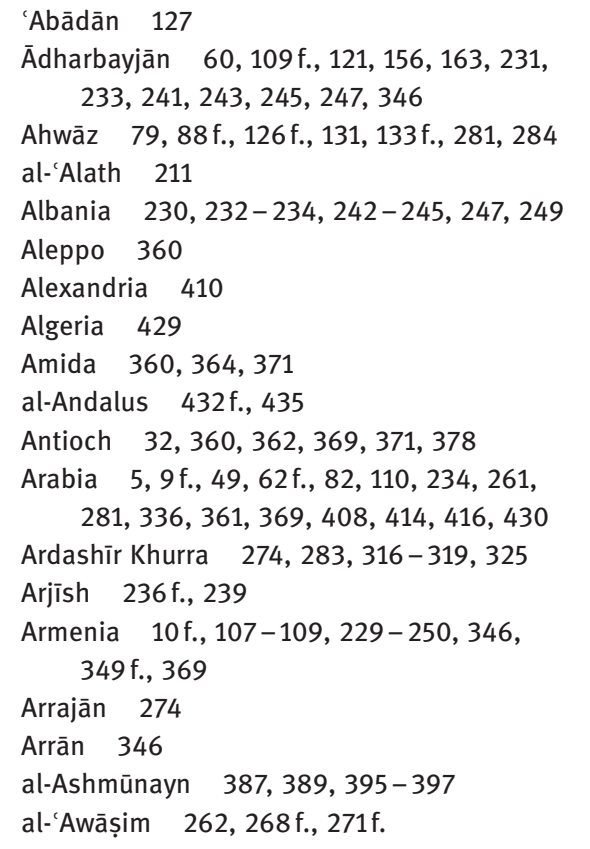

Bāb al-Abwāb, see Darband

Baghdad 1, 5, 10, 14, 70-72, 79, 82 f., 99101, 103, 105-108, 110 f., 118, 132, 154, 156 f., 159, 161-163, 205-208, 210 f., 218, 229, 237-240, 242f., 284, 310, 327, 333, 337f., 340, 343-345, 347, 350, 360, 363 f., 374 f., 402, 412, 421, 427 f., 437

Baghrawand 229, 234, 236-240, 249

Bahrrayn 137, 272, 274, 326

Balīkh 336, 340

Balkh 177, 183, 198f., 202-204

al-Balqā' 62

Bardha'a 109, 244

Bașra 1, 12, 14, 38, 69-71, 73, 79, 81-85, $87,89,92,100,102-104,106,111 \mathrm{f}$. , 126 f., $274-283,285$ f., 288 f., $315-319$, 322, 325 f., 343 f., 421, 424-428, 430, 435- 437

Bayḍā' 131, 133, 135, 137
Bēth Aramayē 76

Bīshāpūr 278

Bukhārā 7, 172f., 176, 247

Bust $108,139-142,177$

Caesarea 32

Caspian Sea 185, 283

Caucasus 102, 109 f., 121, 231

Central Asia 1, 4 f., 11, 14, 37, 99, 171, 173$176,181,193,199,213$ f., 262, 270-273

China 120, 204

Cordoba 428, 432

Cyprus 266, 344

Cyrrhus 372

Dabīl 241

Dābiq $187,189 \mathrm{f}$.

Damascus 59, 61, 72, 151f., 188, 233, 257, 262-267, 269-273, 279, 297, 300, $302-307,311,313,328,349,363,374$, 416

Dārā $\quad 367,373,378$

Darābjird 127, 274, 276, 282, 316 f., 319, $323 \mathrm{f}$.

Darband 109, 231, 234, 236, 241

Daylam 121, 244

Dayr 'Āqūl 80, 135

Dikdān 124, 128

Diyār Muḍar 314, 332f., 336, 340

Diyār Rabī'a 157, 333, 346

Edfū $389,393 \mathrm{f}$.

Egypt $\quad 4-6,13$ f., 19, 50-52, 54-58, $100-$ $102,104,107,111,150,164,188,217$, 267, 270 f., 304, 309-311, 327, 334, 336f., 343, 352, 361, 369f., 387-393, 395-397, 401-403, 407-410, 412416, 429, 435

Euphrates $\quad 71,79,106,108,333,340$

Farghāna $\quad$ 195, 203, 247 
Fārs $\quad 2,10-12,17,35,38,77,88,102 \mathrm{f}$., $117-142,150,153,233,255-260,272-$ $289,315-329,430,432$

Fasā 282f., 317, 319, 323, 325, 328

Fayyūm 391, 395, 409

Fazāra 277, 279

Fazzān 435

Fez 429, 432

Filasțīn 262-264, 265f., 269, 272f., 297, 302, $304 \mathrm{f} ., 313,363,368,413,415$

Fusțāṭ $\quad$ 4, 14, 52, 55 f., 58, 62, 389, 392, 394, 397, 399, 401, 403, 407-410, 413, $415 \mathrm{f} ., 418,421,435,437$

Ganja 109

Geniza 403

Georgia 232f., 239

Ghazna 136

Greater Mesopotamia, see Mesopotamia

Gubba Barraya 365, 372, 378

Haḍramawt 51, 59, 188

Hamadhān 282f., 327

Ḥarrān 12, 37, 241, 331, 333, 335-348, $350-352,367 f ., 371,373,375-377$

Hijāz 279, 315, 339, 432, $435 \mathrm{f}$.

Ḥimṣ $\quad 62,257,262,264$ f., 272, 297 f., 302, 349,364

Hindu Kush 147

al-Ḥira 59, 79, 180, 364

Hurmuzān 124

Ifrīqiya $\quad 2,4,7,10,17,35,38,56,104,150$, 422, 433, $435 \mathrm{f}$.

India $40,120,362$

Indian Ocean 244

Iran 2, 5, 11, 79, 99, 102f., 111, 117, 119, 121f., 129, 158, 174, 199, 231, 276, 282, 429

Iraq 9f., 53f., 59, 61-63, 65, 69-76, $78-85,87 \mathrm{f} ., 90,92 \mathrm{f} ., 99,102 \mathrm{f} ., 110 \mathrm{f} .$, $117,123,126,129,141,150,152,154$, 157, 164, 180-182, 190, 202, $204 \mathrm{f}$., 207 f., 214 f., 238 f., 268, 273-279, 281, 283-285, 287, 321, 327, 333 f., 336, 339, 342, 346, 349, 361f., 364, 369, 414, 424-430, 432, $436 \mathrm{f}$.
Ișfahān $\quad 118,123,183$

al-Iskandariyya 57

Ișțakhr 126, 128, 131, 133, 140 f., 274, 277, $281,283,316 \mathrm{f} ., 323-326$

Jabal Nafūsa 427, 429, 435

Jarjarāyā 80

Jazīra 2, 5, 10, 12 f., 17, 34 f., 77, 89 f., 105$107,109,150,156,207,211,233-235$, 249, 262, 270f., 304, 311f., 314, 327, $331-352,359-378$

Jerusalem 177, 372

Jordan, see al-Urdunn

Jullāb 336

Jundayshāpūr 79, 135

Jūr 283, 319, $324 \mathrm{f}$.

Jurjān 185, 195, 235, 244

Kāriyān 131

Karka d-Beit 77

Kaskar 76

Khilāt $236 \mathrm{f.,} 239$

Khurāsān ～2, 4 f., 9-11, 14, 17, 35, 81, 99, 102, $104-107,109-111,121,125,129$, 139, 147, $150-155,157$ f., 161-164, 171, 182-185, 191-193, 195-197, 201-203, 207, $209-211,215-217,229-231,233-$ $249,260,270,275,279,281,308,316$, 319, 321, 324, 327f., 334, 349, 426, $428-430,435$

Khwārazm 426, 430

Kirmān 130, 136, 140, 277, 281, 283, 285, $287,320,327,430$

Kūfa $\quad 1,10,52 f ., 58-60,63,65,71,73,75$, 77, 84, 93, 110 f., 125, 176, 182 f., 189, 204, 218, 275, 315f., 318, 322, 344, 349, 426, 435

Kuwar Dijla 160, 281, 326

Lake Chad 435

Ma'dan Bājunays 244

Mādarāya 80

Maghrib $1,4,9,14,56,102,104,147,257$, $268,270,272,288,421-437$

Malațya 107

Manbij 112 
Marga 362, 364

Marw 99, 152, 161, 171, 183, 195-197, 209, 216, 242, 244, 248

Marw al-Rūdh 105 f., 240

al-Masrukhānān 84

al-Mașșișa 343

al-Mawșil 1, 12, 100, 156f., 163, 189, 217, 233, 235, 299, 331, 333-337, 346-352, $360,370-372,374$

Maypherkat 366-368, 371

Maysān $75 \mathrm{f} ., 78$

Mecca 14, 51, 55, 82, 99, 156, 201f., 268, 272, 305, 342 f., 414f., 421, 426 f., 435, 437

Medina $\quad 61,110,195,272,298,303,305$, 414, 426, 432

Medīnat al-Fayyūm 389

Mediterranean 9, 370, 423, 433-435

Mesopotamia 1f., 5f., 9, 35, 77, 80, 332, 334, 340, 361, 370 f., 377

Monastery of Gabriel of Kashkar 78

Monastery of Mār Sawrīsho' 78

Mosul, see al-Mawșil

al-Murghāb 93

Nahrawān 80,424

al-Najaf 205

Nașībīn $\quad 333-335,366,370$

Nīshāpūr $\quad 88,118,122$

Nisibis, see Nașībīn

North Africa, see Maghrib

Northern Mesopotamia, see Jazīra

Oxus 184

Palestine, see Filasțīn

Persian Gulf $127,260,274,281-283,428$

Pumbedita 76

al-Qādisiyya $\quad 58,176,180$

Qālĩqalā 236, 239

Qartmin 365

Qayrawān 429, 433, 435, 437

Qazwīn 118

Qenneshre 365, 378

Qinnasrīn 152, 241, 262f., 265, 268-272, 304, 306, 374
al-Rāfiqa $\quad 337,340$

Rāmjird 128, 131

Ramla 415

Raqqa $12,32,70,207,218,331,333-337$, $339-352,375 \mathrm{f}$.

Rayy 78, 111, 182f., 233, 345, 349

Reshaina 366

al-Ruhā $\quad$ 152, 332, 334, 336, 359, 364, 371f., $374-376$

al-Ruṣāfa 198,337

Sābūr 257, 260, 274, 283, 319

Sahara 14, 421, 429, 435, 437

Sa'īdābād 128f., 131, 139

Samarqand 7, 122, 158, 172f., 185, 193, 196, 213, 244, 247

Sāmarrā' 1, 5, 12, 14, 100, 129 f., 137, 157, 176, 213, 248, 272f., 284289, 343, 350, 421, 428 f., 437

Șan'ā' 243

Sawād 70f., 74 f., 80, 86, 90, 92, 111, 160, 273

Sedrata, see Wārjlān

al-Shām 2, 5, 7, 10, 12, 14, 17, 35, 53-55, 62, 72, 82, 99, 102f., 107, 111f., 117, 150, 152, 157, 187, 202, 237 f., 255-258, 261-273, 276, 278, 281, 285-289297314, 333 f., 339 f., 343, 349, 360f., 369, 377, 407, 413-415

Shīrāz 122, 135, 244, 319, 324, 327

Șiffīn 54, 63

Sijilmāsa 425, 429, 435

Sijistān, see Sīstān

Sind 99, 104, 247, 320, 326

Sīrāf 135, 283, 327, 428

Sīstān 108, 135, 137, 140 f., 153, 155, 158, 162f., 177, 233, 241, 274, 320, 430

Soghdia $3 f ., 7,123,173,175,185,191,199$, 213

Spain 51

Sudan 49 f., 433 f., 436

Sūrā $75 \mathrm{f}$.

Syria, see al-Shām

Tabāla 82,279

Ṭabaristān 162f., 185, 233, 241, 349

Tāhart 421-430, 432-437 
al-Ṭā'if $\quad 82,279$

Takrit $\quad 360,364,368-372,374,377$

Tangier 429

Tarsūs 201

Tawwaj 274

Tella 367

al-Thughūr $\quad 262,268,271 \mathrm{f} ., 339$; see also frontier

Tiberias 415

Tibet 244, 283

Tiflīs 236, 238, 247

Tigris 71f., 127, 154, 281, 333, 346

Tilimsān 56

Transoxania 11, 14, 122, 158, 161, 172, 175f., 182-185, 191-196, 199, 203, 214, 216f., 229, 233f., 243, 245-249

Tripolitania $421,423,425$ f., 428
Ṭūr 'Abdīn $\quad 333$, 362, 364, 366-368, 373

Ṭūs 99, 152, 158f., 163, $186 \mathrm{f}$.

'Umān 103, 105, 124, 274, 326, $426 \mathrm{f}$.

al-Urdunn 62, 262-264, 266, 272f., 298, 301f., 313

Van $118,229,429$

Wārjlān 429

Wāsiṭ $\quad 1,71,78,82,84,106,132,158$ f., 428

Yemen $108,120,188,261,272,279,305$, 426, 430

Zāb 7, 152

Zawīla 429, 435 